\title{
EXISTENCE AND UNIQUENESS OF THE SOLUTIONS OF THE NONLINEAR IMPULSE DIFFERENTIAL EQUATIONS WITH NONLOCAL BOUNDARY CONDITIONS
}

\author{
Yusif Gasimov $^{1}$, Misir Mardanov², Yagub Sharifov², Rita Sardarova ${ }^{3}$, and H. Jafari ${ }^{4}$ \\ ${ }^{1}$ Azerbaijan University \\ ${ }^{2}$ Azerbaijan National Academy of Sciences Institute of Mathematics and Mechanics \\ ${ }^{3}$ Azerbaijan State University of Economics \\ ${ }^{4}$ University of South Africa - Florida Campus
}

October 3, 2020

\begin{abstract}
In this paper the system of ordinary impulse differential equations with nonlocal conditions is investigated. First, the boundary value problem is reduced to the equivalent integral equation. Further, using the fixed point theorem, conditions for the existence and uniqueness of the solution of the boundary value problem are obtained. The continuous dependence of the solutions on the right-hand side of the boundary conditions is also established.
\end{abstract}

\section{Hosted file}

Gasimov-Jafari-paper.pdf available at https://authorea.com/users/364136/articles/484658existence-and-uniqueness-of-the-solutions-of-the-nonlinear-impulse-differentialequations-with-nonlocal-boundary-conditions 